\title{
Sporcularda FHL ve os trigonum problemleri
}

\author{
FHL and os trigonum problems in sports
}

\author{
Tahir Öğüt ${ }^{1}$, Necip Selçuk Yontar ${ }^{2}$ \\ ${ }^{1}$ İstanbul Üniversitesi, Cerrahpaşa Tıp Fakültesi, Ortopedi ve Travmatoloji Anabilim Dalı, İstanbul \\ ${ }^{2}$ Nişantaşı Ortopedi Merkezi, İstanbul
}

\begin{abstract}
Os trigonum sendromu ve fleksör hallusis longus (FHL) tenosinoviti, ayak bileğinin tekrarlayan plantarfleksiyonunu gerektiren bale, futbol, basketbol gibi sporlar ile ilgilenenlerde sık karşılaştığımız patolojilerdir. Hastalar, ayak bileği posteriorunda ağrı şikayeti ile başvururlar. Ayak bileği posterolateralinde ağrı ve posterior sıkışma testi pozitifliği, os trigonum sendromu için tipik bulgulardır. FHL tenosinovitinde ise hastalar ayak bileği posteromediyalinde ağrıdan şikayetçi olurlar. Fizik muayenede malleol posteriorunda derin palpasyonda ağrı tespit edilir. Os trigonum sendromu tanısında öykü ve fizik muayene çoğu zaman yeterli olmakla birlikte, ayakta basarak çekilmiş ayak bileği lateral grafilerinde de os trigonum varlığı ortaya konur. Grafilere ek olarak, manyetik rezonans görüntüleme ile de FHL tenosinoviti gibi eşlik eden yumuşak doku patolojileri tespit edilebilir. Aktivite modifikasyonu, istirahat, anti-inflamatuvar ilaç kullanımı, buz uygulaması gibi tedaviler ile şikayetler kontrol altına alınabilir. Konservatif tedaviye rağmen şikayetleri devam eden hastalarda açık veya artroskopik cerrahi tercih edilebilir. Günümüzde düşük komplikasyon oranı ve kısa iyileşme süreci nedeniyle artroskopik müdahale tedavide altın standart olarak kabul edilmektedir.
\end{abstract}

Anahtar sözcükler: os trigonum; FHL; tenosinovit; ayak bileği sıkışma sendromu
Os trigonum syndrome and flexor hallucis longus (FHL) tenosynovitis are frequently encountered problems in patients who regularly participate in activities that require hyperplantarflexion of the ankle such as ballet, football or basketball. Patients complain of posterior ankle pain. Pain on the posterolateral side of the ankle and positive posterior impingement test are typical findings of symptomatic os trigonum. Patients with FHL tenosynovitis usually have pain at the posteromedial ankle, and their physical exam reveal pain along the posteromedial ankle with deep palpation. Os trigonum syndrome can readily be diagnosed with history and physical examination findings but weight-bearing lateral radiographies can also reveal os trigonum. Accompanying soft tissue pathologies like FHL tenosynovitis can be diagnosed with the help of magnetic resonance imaging. Nonoperative management typically involves modification of activities, rest, oral anti-inflammatory medications and ice application. Dissatisfied patients with the outcomes of conservative treatment are candidates for open or arthroscopic surgery. Because of the lower complication rates and faster recovery, arthroscopic surgery is accepted as the golden standard for the treatment of these pathologies.

Key words: os trigonum; FHL; tenosynovitis; ankle impingement syndrome

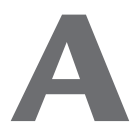

yak bileği posterior sıkışma sendromu (PAIS) ve fleksör hallusis longus (FHL) tendon problemleri, ayak bileğinin tekrarlayan plantarfleksiyonunu gerektiren sporlar ile ilgilenenlerde sık karşılaştığımız patolojilerdir. ${ }^{[1-4]}$ PAIS tanısı klinik bulgular ışığında konulur ve hiperplantarfleksiyonda ayak bileği arkasında hissedilen ağıı ile karakterizedir. ${ }^{[5,6]}$ En sık karşılaşılan nedenleri, posterolateral talar çıkıntıyı ilgilendiren patolojiler olan Stieda process (belirgin posterolateral çıkıntı) ve os trigonumdur. Bunun yanında; akut kırıklar, aşırı kullanım, subtalar veya tibiotalar eklemde dejeneratif artrit ve kırık sonrası yanlış kaynama da PAIS ile ilişkili olabilir. ${ }^{[5,7]}$

FHL tendon patolojileri ise stenozan tenosinovit olarak karşımıza çıkar. Patoloji tendon trasesi boyunca görülebilir, ancak tenosinovit ile en sık mediyal malleol posteriorunda yer alan fibroosseöz tünel seviyesinde karşılaşılır. ${ }^{[8]}$ Bu durum, tendon içerisindeki avasküler kesimin bu seviyede olması ya da tendon ile tünel boyutları arasındaki uyumsuzluk kaynaklı görülebileceği gibi, tendon içerisindeki nodüler lezyonlar, tendon hipertrofisi, aksesuvar FHL tendonu

- İletişim adresi: Uzm. Dr. Necip Selçuk Yontar, Dikilitaş Mahallesi, Hakkı Yeten Caddesi, Süleyman Seba Kompleksi, $10 \mathrm{D}$, 34728 Beşiktaş, İstanbul Tel: 0212 - 2252049 e-posta: nsyontar@hotmail.com

- Geliș tarihi: 1 Ocak2018 Kabul tarihi: 1 Ocak 2018 
veya aşağıda yer alan kas gövdesi gibi patolojiler de tenosinovite neden olabilir. ${ }^{4,8-10]}$ Bunlar dışında, FHL tendonu ayak birinci parmağına doğru olan seyri esnasında talus posteriorunda mediyal ve lateral tüberküller arasındaki olukta bulunur. Bu anatomik yakınlıktan dolayı, FHL tenosinoviti ve PAIS birlikteliği ile sık karşılaşılır. Scholten ve ark. PAIS hastalarının \%63'ünde FHL tutulumu olduğunu bildirirken, Öğüt ve ark., 59 hastalık serilerinde hastaların tamamında PAIS ile birlikte FHL tutulumu olduğunu belirtmişlerdir. ${ }^{[6,11]}$ FHL tenosinoviti izole olarak da görülebileceği gibi, klinik pratiğimizde posteriorda yer alan talus osteokondral lezyonlarında ve intraosseöz kist gibi olgularda da FHL tenosinovitinin klinik tabloya eşlik ettiğini görmekteyiz. ${ }^{[12]}$ Bu durumun, reaktif sinovit, kapsüler hipertrofi veya aşırı skar dokusuna bağlı olabileceği düşünülmektedir.

\section{Os Trigonum}

Bilindiği gibi, os trigonum talusun sekonder ossifikasyon merkezinin kaynamaması ile ilişkili görülen aksesuvar kemiktir. FHL tendonunun yer aldığı oluğun lateralinde yer alır ve kızlarda 8-10 yaşları arasında, erkeklerde ise 11-13 yaşları arasında gözlenmeye başlar. ${ }^{[13]}$ Toplum içerisinde görülme sıklığı \%1,7-7,7 arasında olup, talus gövdesine fibrokartilajinöz bir sinkondroz ile bağlıdır ve genellikle asemptomatiktir. ${ }^{[1,14]}$ Ancak; akut travmalar veya aşırı kullanım (overuse) sonrasında semptomatik hale gelebilir ve os trigonum sendromu olarak anilır. ${ }^{[3,5,13,14]}$ Os trigonum sendromu en sık klasik bale ile ilgilenen dansçılarda karşımıza çıkar. Relevé en pointe, demipointe veya tendu pozisyonunda gereken ayak bileği plantarfleksiyonu, bu durumun sorumlusudur. ${ }^{[3]}$ Bale dışında ayak bileğinin tekrarlayan zorlu plantarfleksiyonunu gerektiren futbol, basketbol, atletizm gibi sporlar ile ilgilenen sporcularda da os trigonum ile ilişkili şikayetlere sık rastlanır.

\section{Fleksör Hallusis Longus}

FHL tendonunun ana görevi, ayak birinci parmağının plantar fleksiyonudur. Bunun yanında; yürüme, koşma, zıplama, tırmanma ve çömelme esnasında dengenin sağlanmasına yardımcı olur. ${ }^{[1]}$ Balede sık kullanılan parmak ucuna kalkma ve sonrasında kontrollü olarak aşağıya inme hareketlerine (relevé ve grand plié) olanak verir. Ancak, tekrarlayan zorlu plantarfleksiyon, tendonun retinakulum ve talar prosesler arasında yer alan olukta sıkışmasına neden olur. ${ }^{[2]}$ Dolayısıyla FHL kaynaklı şikayetlere de bale, futbol, basketbol gibi sporlar ile ilgilenen bireylerde daha sık rastlanır. Ancak, FHL problemlerinin atletik olmayan kişilerde de görülebileceği unutulmamalıdır.

\section{HIKAYE ve FIZIK MUAYENE}

\section{Os Trigonum}

Os trigonum sendromunda, ayak bileği arkasında hissedilen ve ayak bileğinin zorlu plantarfleksiyonu ile artan ağrı en sık karşılaşılan şikayettir. Aktivite sonrasında belirgin olan ağrı, istirahat sonrası geriler. Ağrıya ek olarak, ayak bileği hareketlerinde kısıtlılık hissi ve ayak bileği arkasında şişlik, görülebilen diğer şikayetlerdir. ${ }^{[13]}$

Fizik muayenede, ağrı genellikle ayak bileği posteriorunda özellikle lateral malleol posteriorundadır. ${ }^{[2]}$ Zorlu plantarfleksiyon ile ayak bileği arkasında ağrının provoke edilmesi PAIS dolayısıyla os trigonum sendromu için tanı koydurucudur. Ayak bileği hareket açıklığında özellikle plantar fleksiyonda kısıtlılık tespit edilebilir. ${ }^{[13]}$

Uzun süreli şikayetleri olan hastalarda ise, fibroosseöz tünel seviyesinde FHL tendonu çevresindeki fibrotik dokular nedeniyle, başparmak hareket açıklığında azalma tespit edilebilir.

\section{FHL Tenosinoviti}

FHL tenosinovitinde hastalar, ayak bileği ve başparmak hareketleri ile artan ağrıdan şikayet ederler. Ağrı tipik olarak ayak bileği posteromediyalinde hissedilir, ancak hastaların topuk plantarı, ayak ortası veya 1 . metatarsofalangeal (MTF) eklem komşuluğunda ağrı ile başvurabilecekleri de akılda tutulmalıdır. ${ }^{[2]}$ Bunun dışında, başparmak hareketlerinde kısıtlanma veya hareket ile eklemde takılma hissi gibi şikayetler ağrıya eşlik edebilir.

Fizik muayenede mediyal malleol posteriorunda derin palpasyonda ağıı tespit edilir. Posterior sıkışma testi pozitif olmayabilir. Ayak bileği ve 1 . MTF eklemin eşzamanlı dorsifleksiyonu ile ağrı provoke edilebilir. Tendonun fibroosseöz tünelde sıkışmasına ve hareketinin kısıtlanmasına bağlı olarak, 1. MTF eklem hareketlerinde kısıtlanma veya tetiklenme izlenebilir. Ayak bileğinin maksimum plantarfleksiyonu ile 1. MTF eklem dorsifleksiyonunda açılma elde edilirse, bu durum psödo-halluks rijidus olarak adlandırılır.

\section{GÖRÜNTÜLEME}

Tüm ayak ve ayak bileği patolojilerinde olduğu gibi, os trigonum sendromu ve FHL patolojilerinde de radyolojik değerlendirme ayakta basarak çekilen ayak bileği anteroposterior (AP) ve lateral grafileri ile başlar. AP grafilerde genellikle bir patoloji izlenmez. Lateral grafilerde ise os trigonum rahatlıkla görüntülenir. Os trigonumun net olarak izlenememesi durumunda ise $25^{\circ}$ eksternal rotasyonda çekilen ayak bileği lateral grafisi kullanılabilir. ${ }^{[15]}$ Ayakta basarak çekilen lateral grafiye ek olarak, ayak bileği plantarfleksiyonda iken 


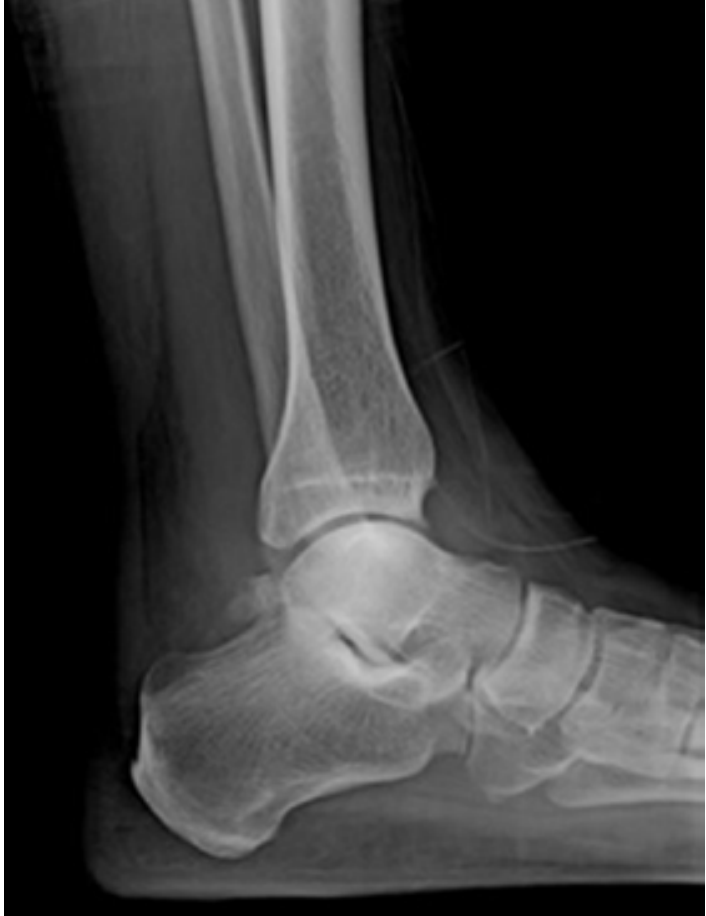

Şekil 1. Ayak bileği lateral grafisinde gözlenen os trigonum.

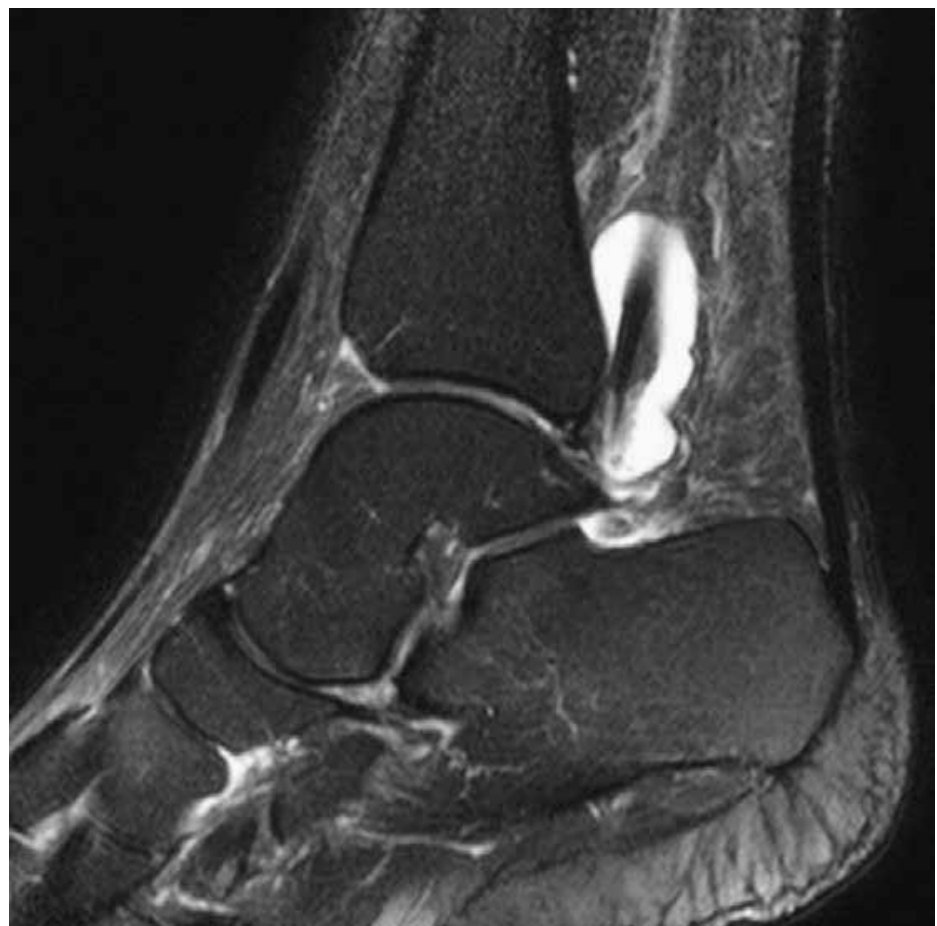

Şekil 2. Sagittal manyetik rezonans kesitinde izole FHL tenosinoviti. çekilecek lateral grafiler sayesinde posterior malleol ile os trigonum arasındaki sıkışma radyolojik olarak da gösterilebilir. ${ }^{[13]}$ Ancak, herhangi bir şikayet olmadan os trigonum izlenmesinin klinik bir öneminin olmadığı unutulmamalıdır (Şekil 1).

Os trigonum sendromu tanısı için fizik muayene ve direkt grafi yeterli olmakla beraber, kemik yapının ayrıntılı değerlendirilmesi veya travma öyküsü olan hastalarda kırık açısından ayrıntılı inceleme amaçlı olarak bilgisayarlı tomografi (BT) kullanılabilir.

Manyetik rezonans (MR) ise posterior kapsül, bağlar, inflame synovium gibi yumuşak doku bozuklukları yanında FHL tendonunun değerlendirilmesinde kullanılır. MR ile FHL kılıfinda effüzyon, tendon içi dejeneratif alanlar ve parsiyel yırtıklar ayrıntılı bir şekilde incelenebilir. FHL tendonunun değerlendirilmesi amacıyla kullanılabilecek bir diğer teknik ultrasonografidir (US). Tendon kılıfi içerisinde sıvı varlı̆̆ı, tendon çevresi nodüler lezyonlar veya os trigonum ile posterior malleol arasındaki sıkışmanın kendisi US ile görüntülenebilir (Şekil 2). ${ }^{[13]}$

\section{KONSERVATIF TEDAVi}

Os trigonum sendromu ve FHL patolojilerinin tedavisinde cerrahi dışı tedavi ilk seçenektir. İstirahat, buz uygulaması, anti-inflamatuvar ilaçlar, fizik tedavi ve ağrıyı arttıran sportif aktivitelerden sakınıması ile, os trigonum sendromu olan hastaların yaklaşık \%60'ında başarılı sonuçlar alınabilir. ${ }^{[16]}$ Bunlara ek olarak uygulanacak kortikosteroid enjeksiyonları, hem tanı hem de tedavi amaçlı olarak kullanılabilir. FHL tenosinoviti olan hastalarda ise FHL germe egzersizleri tedavi planına eklenebilir. FHL kaynaklı şikayetlerde konservatif tedavinin uzun bir süreç alabileceği akılda tutulmalı ve şikayetlerin tam olarak geçmeme ihtimali hastalar ile paylaşılmalıdır. ${ }^{[7]} \mathrm{Bu}$ nedenle de, sporcularda cerrahi tedavi daha erken dönemde tercih edilebilir.

\section{CERRAHI TEDAVi}

Konservatif tedaviye rağmen şikayetleri devam eden veya erken dönemde spora dönmesi gereken sporcularda cerrahi tedaviye karar verilir.

\section{Açık Cerrahi}

Os trigonum sendromu tedavisinde posteromediyal veya posterolateral yaklaşımlar kullanılabilir. ${ }^{[17]}$ Posterolateral yaklaşımda fibula posteriorunda yer alan bir insizyon üzerinden girilir ve Aşil ile peroneal tendonlar arasında ilerlenerek, posterior kapsüle ulaşılır. ${ }^{[13]}$ Bu yaklaşımda risk altındaki yapılar, sural sinir ve küçük safen vendir. Abramowitz ve ark. da, posterolateral yaklaşım üzerinden os trigonum eksizyonu uyguladıkları 41 hastalık serilerinde dört kalıcı, dört geçici 

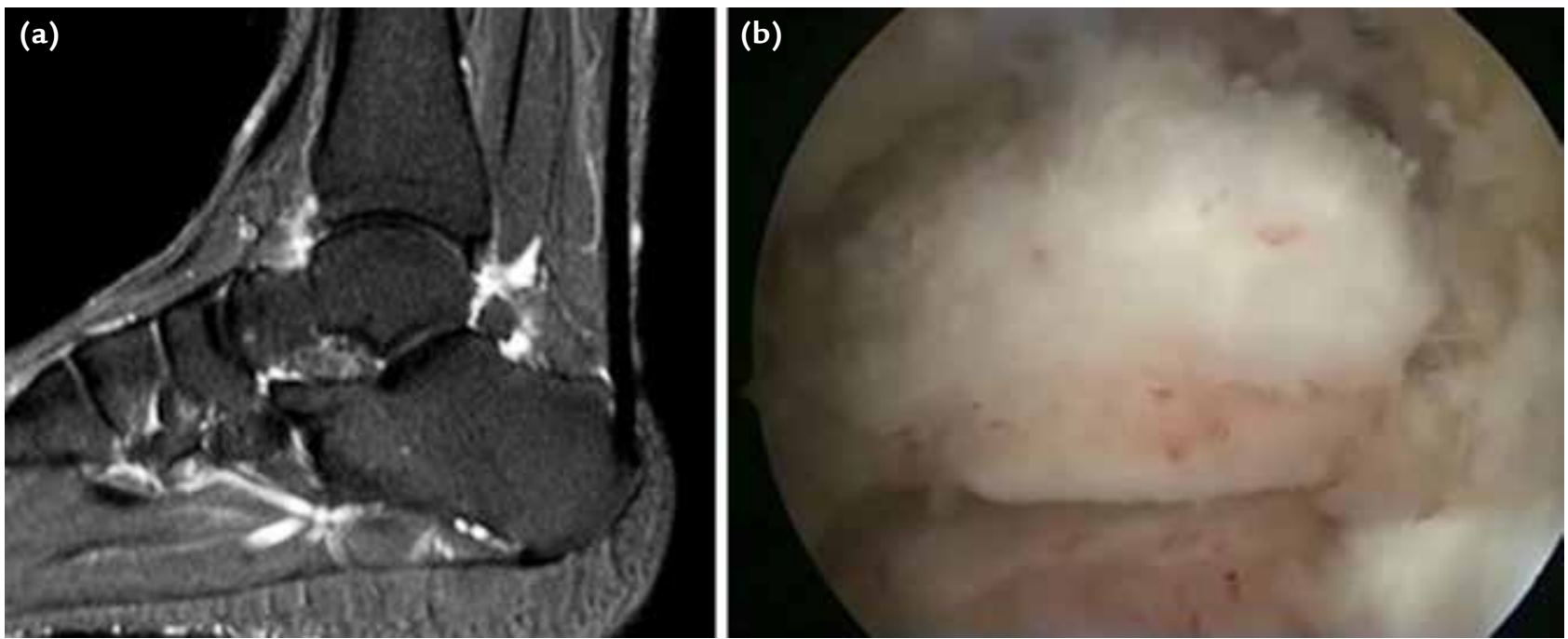

Şekil 3. a, b. Ameliyat öncesi sagittal MR kesitinde izlenen os trigonumun artroskopi esnasında (a) ve eksizyon sonrası (b) görünümü.

sural sinir hasarı yanında, bir hastada yüzeyel yara yeri enfeksiyonu ve bir hastada da kompleks bölgesel ağıı sendromu ile karşılaştıklarını bildirmişlerdir. ${ }^{[18]}$ Georgiannos ve ark., posterolateral yaklaşım ve endoskopik yaklaşımı karşılaştırdıkları randomize kontrollü çalışmalarında, açık cerrahi uyguladıkları 26 hastada \%23 (iki yüzeyel enfeksiyon, iki sural sinir nöropraksisi, bir kompleks bölgesel ağrı sendromu ve bir kalıcı sural sinir hasarı) oranında komplikasyon ile karşılaştıklarını bildirmişlerdir. ${ }^{[19]}$ Posterolateral yaklaşımın bir diğer dezavantajı, FHL patolojilerinin tespit edilmesinde karşılaşılan zorluktur. Heyer ve ark., posterolateral yaklaşım sonrasında devam eden ağrının, cerrahi esnasında tespit edilemeyen ve dolayısıyla tedavi edilemeyen FHL tendon patolojileri kaynaklı olduğu öne sürmektedir. ${ }^{[3]}$ Bundan dolayı, özellikle eşlik eden $\mathrm{FHL}$ patolojisi olan hastalarda posteromediyal yaklaşım tercih edilebilir. Bu yaklaşımda, mediyal malleol posteriorunda yapılacak insizyon üzerinden nörovasküler demet ortaya konup, korumaya alınır. Ardından, os trigonum yanında eşlik eden FHL tenosinoviti de tedavi edilebilir. ${ }^{[1]}$ Heyer ve ark., posteromediyal yaklaşım üzerinden os trigonum eksizyonu uyguladıkları 38 hastanın 40 ayak bileğinde majör komplikasyon ile karşılaşmadıklarını, yalnızca dört (\%10) hastada minör yara yeri problemleri ile karşılaştıklarını bildirmişlerdir. ${ }^{[3]}$

\section{Artroskopik Cerrahi}

Daha düşük komplikasyon oranları, ayak bileği posteriorunun ayrıntılı görüntülenebilmesi, daha hızlı iyileşme süresi, sportif aktivitelere daha hızı dönüş ve daha düşük morbidite gibi avantajları nedeniyle, günümüzde artroskopik cerrahi PAIS ve FHL tenosinovitinin tedavisinde altın standart olarak kabul edilmektedir. ${ }^{[6,19]}$ Bununla birlikte, öğrenme eğrisinin uzun olması ve artroskopi portallerinin nörovasküler yapılara yakınlığı, uygulamada zorluklara neden olmaktadır.

Artroskopik tedavide, van Dijk tarafından tanımlanmış posterior ayak bileği artroskopisi portalleri üzerinden girilir. ${ }^{[20]}$ Öncelikle yağlı dokular ve skar dokusu shaver yardımı ile temizlenir. FHL tendonu ortaya konduktan sonra, tendonun lateralinde kalınarak nörovasküler demet korumaya alınır ve bu sayede iyatrojenik sinir hasarı riski ortadan kaldırılır. ${ }^{[5]}$ Ardından, subtalar eklem ve os trigonum görüntülenir ve shaver, osteotom veya burr ile, sıkışma yapan dokular ile birlikte os trigonum eklemden uzaklaştııılır. Os trigonumun çıkarılmasını kolaylaştırmak amacıyla posterior talofibular bağ, FHL retinakulumu ve posterior talokalkaneal bağın os trigonumdan serbestleştirilmesi gerekir. ${ }^{[10]}$ Bu esnada, başparmak hareketleri ile FHL tendonu çevresinde sıkışmaya neden olan dokular görüntülenebilir ve shaver yardımı ile tendon serbestleştirilir (Şekil 3).

Günümüzde ardayak artroskopisi en sık os trigonum sendromu nedeniyle uygulanmaktadır ve bu hastaları içeren yayınların hepsinde artroskopik müdahale sonrasında klinik iyileşme elde edildiği bildirilmektedir.[21] Jerosch ve ark., artroskopik os trigonum eksizyonu sonrasında, ameliyat öncesinde ortalama 43 olan AOFAS skorunun ameliyat sonrası kontrol muayenesinde ortalama 87'ye yükseldiğini, benzer şekilde Morelli ve ark., ameliyat öncesi ortalama 67,8 olan AOFAS (American Orthopedic Foot and Ankle Society) skorunun 38,9 aylık ortalama takip sonrasında 96'ya yükseldiğini bildirmişlerdir (Şekil 4). ${ }^{[14,18]}$ 

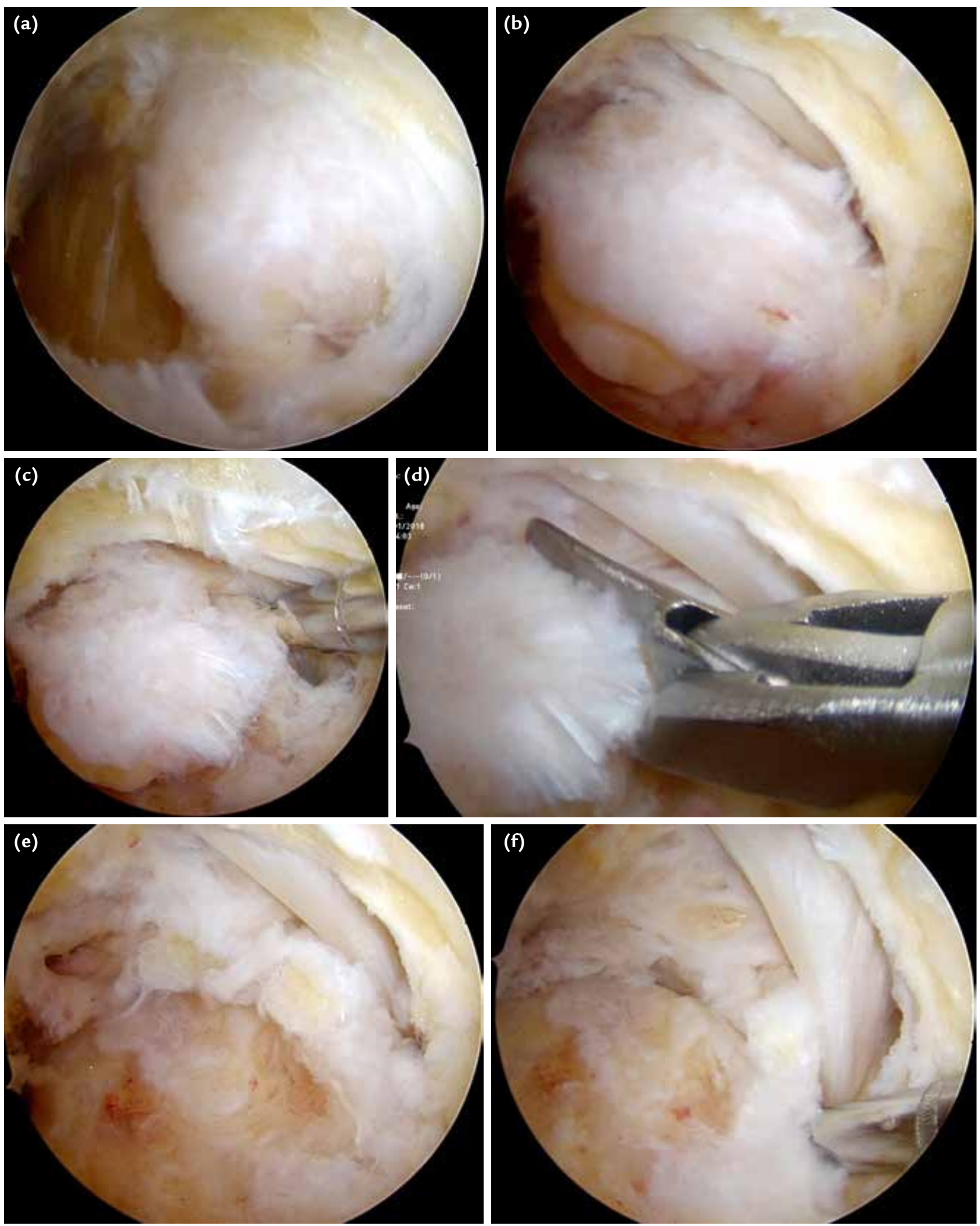

Şekil 4. a-f. Altmış iki yaşında erkek hasta. Os trigonum sendromu ve FHL tenosinoviti nedeniyle artroskopik teknik ile tedavi edildi. Shaver ile yağlı dokular temizlendikten sonra os trigonumunun ilk görünümü (a). Os trigonum ve komşuluğunda $F H L$ tendonu (b). Os trigonum çevresinin serbestleştirilmesi ardından görünüm (c). Os trigonumun talustan serbestleştirilmesi (d). Os trigonumun eksizyonu sonrası görünüm (e). FHL tendonunun trasesi boyunca distale doğru serbestleştirilmesi (f). 

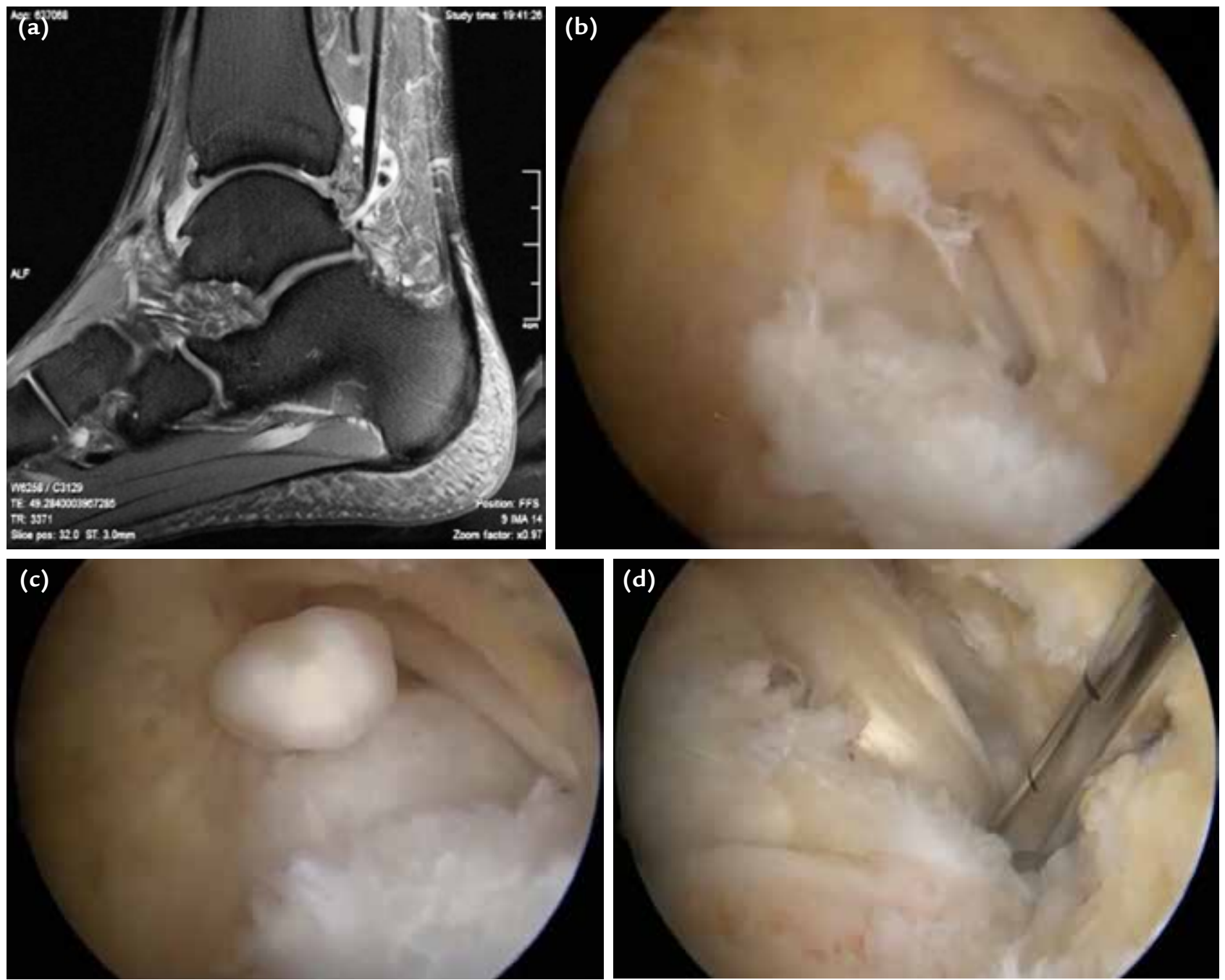

Şekil 5. a-d. Otuz bir yaşında profesyonel basketbol oyuncusu hastamızın ameliyat öncesi sagittal MR kesitinde izlenen FHL tenosinoviti ve tendon komşuluğundaki kondromatöz serbest cisim (a). Artroskopik müdahale esnasında FHL tendonunun ilk olarak görüntülendiği an (b). Ameliyat öncesi MR'de de izlenmekte olan serbest cisim (c). FHL tendonunun trasesi boyunca distale doğru serbestleştirilmesi (d).

İzole FHL tenosinoviti için uygulanan müdahale sonrasında da Corte-Real ve ark., hastaların \%70'inde iyi veya mükemmel sonuç elde ettiklerini ve \%81'inin ameliyat öncesi aktivite seviyelerine dönebildiklerini bildirmişlerdir. ${ }^{[8]}$ Öğüt ve ark. da, izole FHL gevşetmesi uyguladıkları 11 hastada AOFAS skorunun 48,7'den 83,2 'ye, Maryland Ayak skorunun ise 49,6'dan 83,1'e yükseldiğini bildirmişlerdir (Şekil 5). ${ }^{[6]}$

Artroskopik müdahalenin komplikasyonlarına bakıldığında, Ribbans ve ark., \%3,7 sinir hasarı ve \%0,96 yara yeri komplikasyonu ile karşılaştıklarını bildirmişlerdir. ${ }^{[17]}$ Nickisch ve ark. ise 186 hastalık serilerinde, \%8,5 oranında komplikasyon ile karşılaştıklarını bildirmişlerdir. ${ }^{[22]} \mathrm{Bu}$ seride bildirilen komplikasyonlar; dört hastada plantar hissizlik, üç sural sinir disestezisi, dört Aşil tendonunda gerginlik, iki kompleks bölgesel ağrı sendromu, iki enfeksiyon ve bir hastada posteromediyal portalde kist oluşumu olarak sıralanmış ve bu komplikasyonlardan bir hastadaki plantar hissizlik ve bir hastadaki sural sinir disestezisi dışında kalanların takipler esnasında iyileştiği bildirilmiştir.

\section{SONUÇ}

Os trigonum sendromu ve FHL tenosinoviti, posterior ayak bileği ağrısının sık karşılaşılan nedenlerindendir. Bunlar, akut yaralanmalar veya sıklıkla aşırı kullanım ile ilişkili olarak izlenir ve özellikle ayak 
bileğinin hiperplantarfleksiyonunu gerektiren bale, basketbol, futbol gibi sporlar ile ilgilenenlerde daha sık tespit edilir. Konservatif tedavi ile başarılı sonuçlar alınabilir, ancak konservatif tedaviye rağmen şikayetleri devam eden hastalarda, açık veya artroskopik cerrahi ile her iki patoloji de başarılı bir şekilde tedavi edilebilir. Günümüzde daha düşük komplikasyon oranları, sportif aktivitelere daha erken dönmeye olanak vermesi ve yüksek başarı oranı nedeniyle, artroskopik müdahale altın standart olarak kabul edilmektedir.

\section{KAYNAKLAR}

1. Coughlin MJ, Schon LC. Disorders of Tendons. In: Coughlin MJ, Saltzman CL, Anderson RB, editors. Surgery of Foot and Ankle 9th ed. Philadelphia, PA: Elsevier Inc; 2007. pp.1149-277.

2. Rungprai C, Tennant JN, Phisitkul P. Disorders of the Flexor Hallucis Longus and Os Trigonum. Clin Sports Med 2015;34(4):741-59. Crossref

3. Heyer JH, Rose DJ. Os Trigonum Excision in Dancers via an Open Posteromedial Approach. Foot Ankle Int 2017;38(1):27-35. Crossref

4. Ögüt T, Yontar NS. Treatment of hindfoot and ankle pathologies with posterior arthroscopic techniques. EFORT Open Rev 2017;2(5):230-40. Crossref

5. Miyamoto W, Takao M, Matsushita T. Hindfoot endoscopy for posterior ankle impingement syndrome and flexor hallucis longus tendon disorders. Foot Ankle Clin 2015;20(1):13947. Crossref

6. Ogut T, Ayhan E, Irgit K, Sarikaya AI. Endoscopic treatment of posterior ankle pain. Knee Surg Sports Traumatol Arthrosc 2011;19(8):1355-61. Crossref

7. Smyth NA, Murawski CD, Levine DS, Kennedy JG. Hindfoot arthroscopic surgery for posterior ankle impingement: a systematic surgical approach and case series. Am J Sports Med 2013;41(8):1869-76. Crossref

8. Corte-Real NM, Moreira RM, Guerra-Pinto F. Arthroscopic treatment of tenosynovitis of the flexor hallucis longus tendon. Foot Ankle Int 2012;33(12):1108-12. Crossref
9. Ogut T, Ayhan E. Hindfoot endoscopy for accessory flexor digitorum longus and flexor hallucis longus tenosynovitis. Foot Ankle Surg 2011;17(1):e7-9. Crossref

10. Smyth NA, Zwiers R, Wiegerinck JI, Hannon CP, Murawski CD, van Dijk CN, Kennedy JG. Posterior hindfoot arthroscopy: a review. Am J Sports Med 2014;42(1):225-34. Crossref

11. van Dijk CN, de Leeuw PA, Scholten PE. Hindfoot endoscopy for posterior ankle impingement. Surgical technique. J Bone Joint Surg Am 2009;91 Suppl 2:287-98. Crossref

12. Ogut T, Seker A, Ustunkan F. Endoscopic treatment of posteriorly localized talar cysts. Knee Surg Sports Traumatol Arthrosc 2011;19(8):1394-8. Crossref

13. Nault ML, Kocher MS, Micheli LJ. Os trigonum syndrome. J Am Acad Orthop Surg 2014;22(9):545-53. Crossref

14. Morelli F, Mazza D, Serlorenzi P, Guidi M, Camerucci E, Calderaro C, lorio R, Guzzini M, Ferretti A. Endoscopic Excision of Symptomatic Os Trigonum in Professional Dancers. J Foot Ankle Surg 2017;56(1):22-5. Crossref

15. Niek van Dijk C. Anterior and posterior ankle impingement. Foot Ankle Clin 2006;11(3):663-83. Crossref

16. Heier KA, Hanson TW. Posterior Ankle Impingement Syndrome. Oper Tech Sports Med 2017;25(2):75-81.

17. Ribbans WJ, Ribbans HA, Cruickshank JA, Wood EV. The management of posterior ankle impingement syndrome in sport: a review. Foot Ankle Surg 2015;21(1):1-10. Crossref

18. Jerosch J, Fadel M. Endoscopic resection of a symptomatic os trigonum. Knee Surg Sports Traumatol Arthrosc 2006;14(11):1188-93. Crossref

19. Georgiannos D, Bisbinas I. Endoscopic Versus Open Excision of Os Trigonum for the Treatment of Posterior Ankle Impingement Syndrome in an Athletic Population: A Randomized Controlled Study with 5-Year Follow-up. Am J Sports Med 2017;45(6):1388-94. Crossref

20. Van Dijk CN, Scholten PE, Krips R. A 2-portal endoscopic approach for diagnosis and treatment of posterior ankle pathology. Arthroscopy 2000;16(8):871-6. Crossref

21. Spennacchio P, Cucchi D, Randelli PS, van Dijk NC. Evidencebased indications for hindfoot endoscopy. Knee Surg Sports Traumatol Arthrosc 2016;24(4):1386-95. Crossref

22. Nickisch F, Barg A, Saltzman CL, Beals TC, Bonasia DE, Phisitkul P, Femino JE, Amendola A. Postoperative complications of posterior ankle and hindfoot arthroscopy. J Bone Joint Surg Am 2012;94(5):439-46. Crossref 